\title{
10
}

\section{Restoring ecosystem services on private farmlands: Lessons from economics}

\author{
Md Sayed Iftekhar, Maksym Polyakov \\ and Fiona Gibson
}

\section{Key lessons}

- Biological conservation attempts to preserve and maintain existing habitat, while ecological restoration attempts to reverse an environmental degradation process.

- The higher cost per unit area (or per ecological outcome) to implement restoration projects, compared with conservation projects, could negatively influence their formation and acceptance.

- Broad support for restoration projects can be difficult to achieve, due to people's loss aversion behaviour.

- Uncertainty in expected biodiversity benefits can influence the acceptance and success of restoration projects.

- Social value could influence the objectives of restoration projects; the more aligned the social and environmental objectives are, the higher the chances of acceptance.

- Some of the biophysical and social benefits of restoration projects could be privately captured, which could increase acceptance of restoration projects. 
- Economic incentives, such as monetary benefits, can play a crucial role in motivating private landholders to participate in agri-environment schemes, but may not be sufficient.

Clearance of the natural environment for farming and intensification of land use on existing farmlands puts pressure on the remaining natural environment (Michael et al. 2014). As a result, there is a decline of species richness as well as biotic homogenisation, as species with high conservation concern are gradually replaced by species with lower conservation concern (Donald and Evans 2006). Protecting and restoring biodiversity on private farmlands can therefore play an important part in provision of ecosystem services.

Governments have recognised the importance of conserving and restoring ecosystem services on private lands through agri-environment schemes. Agri-environment schemes have been developed in Australia (e.g. Bush Tender), the US (e.g. Conservation Reserve Program), and the European Union (e.g. Common Agricultural Policy). Under these programs, landholders receive government support in exchange for undertaking environmental management actions, such as ecological restoration.

Traditionally, ecological restoration activities and projects have been targeted, prioritised, and planned using ecological considerations (Aronson et al. 2006). Only recently have ecologists begun to include economic and social considerations in the design of restoration projects (Blignaut et al. 2014). With few exceptions, ecological restoration studies that include economics focus only on the cost side of restoration projects (Bullock et al. 2011; Wilson et al. 2012). Incorporating proper cost estimates in benefit-cost analysis is essential to make sound economic decisions in terms of the selection and prioritisation of restoration projects. However, economics can contribute more broadly to restoration programs. Lessons from economics could assist in the conceptualisation and planning of programs, reveal factors affecting program acceptance and uptake, and inform the design of restoration programs to increase success. In this chapter, we summarise some of the key lessons from economics that we hope will help improve the effectiveness and efficiency of ecological restoration and agrienvironmental schemes. 


\section{Comparing costs from ecological restoration and conservation projects}

Restoration projects, which are primarily aimed at restoring ecosystems of varying levels of degradation, are generally more costly than conservation projects, which are aimed at the protection of existing ecologically intact ecosystems (Blignaut et al. 2014). Some types of costs are common for both restoration and conservation projects (e.g. opportunity and maintenance costs). However, establishment costs are likely to be much higher for restoration projects, which require a variety of restoration actions with different levels of intensity (Hobbs and Cramer 2008). These actions range from allowing the ecosystem to recover without human interference - commonly referred to as passive restoration - to actively undertaking a restoration process. In agricultural landscapes, ecological restoration usually requires active intervention (Polasky et al. 2005).

The opportunity cost of ecological restoration is often much higher than the opportunity cost of creating a reserve in an undisturbed natural landscape, for the following reasons:

- Restoration projects tend to occur on intensive production, highervalue land, such as agricultural or mining landscapes, whereas conservation projects are usually located on lower-value land, such as grazing land.

- Restoring ecosystems on land impacted by intensive production is often more costly than on land used for other less-intensive purposes due to a greater rate of land use modifications.

- Restoration is an intensive process and restoration projects tend to be of a smaller scale than conservation projects, which increases both the cost per hectare of restoring small sites and the overhead costs associated with managing many smaller projects.

- Ecological restoration is undertaken when reservation of intact habitat is not an option. Such landscapes tend to be highly fragmented, which could also influence ongoing maintenance costs of restoration projects (Lindenmayer et al. 2002; McBride et al. 2010). 
The success of ecological restoration projects is determined by their ecological proximity and connections to existing habitats. Ecological synergy benefits from the existing protected areas influence the capacity of the restored sites to generate ecosystem services (Bennett et al. 2006; Manning et al. 2006). Therefore, the spatial arrangement and characteristics of existing habitats inside and outside the planning areas need to be carefully considered. Otherwise, restoration projects are likely to be less effective and require higher operation costs to generate the same amount of environmental outcome (Thomson et al. 2009).

\section{Support for restoration projects can be difficult to obtain due to people's loss aversion behaviour}

Gaining social support for restoration projects can be difficult, compared to conservation projects, due to people's loss aversion behaviour. It has been observed that people are more sensitive to changes seen as losses than to gains of the same magnitude (Tversky and Kahneman 1992). For example, let us assume that an individual owns $\$ 100$. According to this theory, she will suffer greater dissatisfaction if $\$ 10$ is taken away from her than the corresponding level of satisfaction if she was given $\$ 10$. In the presence of loss aversion behaviour, people may be more inclined to support a conservation project that proposes to protect a bushland (preventing it from being lost) than a restoration project that would restore a bushland of the same area and quality (which could mean losing productive land). Uncertainty in expected environmental outcomes of a restoration project would increase people's loss aversion behaviour.

\section{Uncertainty in expected ecological outcomes can influence the adoption and success of restoration projects}

When designing conservation programs, decision makers often have a target of what they plan to conserve or protect, even though in most cases the target is poorly defined. With restoration programs, 
the target is a desired environmental outcome (Yoshioka et al. 2014). These predictions are based on ecological and biophysical models, such as tree growth models or species distribution models. Even if these models use the best available data and advanced modelling techniques, there can be substantial uncertainty in their predictions (Haila et al. 2014). The probability that a restoration project will deliver the expected outcomes depends not only on the on-ground actions but many other factors, such as environmental condition, restoration technique, and socio-economic factors (Lindenmayer et al. 2002; Maron et al. 2012; Raymond and Brown 2011). Failure to take account of these uncertainties diminishes the benefits of ecological restoration. However, so far, the probability of success of restoration projects has rarely been factored into the ecological-restoration planning process (Dorrough et al. 2008).

\section{Social value could influence the objectives of restoration projects}

The objectives of restoration projects are likely to be influenced by social values. Values for conservation projects are easier (more certain) to obtain because what is there, in terms of biodiversity, is known, and the probability of conservation project failure is arguably lower than a restoration project (Robbins and Daniels 2012). For restoration, the final condition is not known due to many uncertainties. For this reason, it is often difficult to set scientific goals for restoration projects. Therefore, restoration efforts require an understanding of community values and preferences, which are highly context-dependent (Shindler et al. 2011) and should necessitate a participatory process to identify goals and aspirations for the site (Schaich 2009; Schultz et al. 2012). For example, Alam (2011) found that people's willingness to pay for restoration of a river in Bangladesh varies with their proximity to resources, their length of residence in the area, and their depth of experience with the area. In Japan, Mitani et al. (2008) found that individuals with strong environmental attitudes, a history of past visitation, and high income are more likely to prefer restoration projects to the status quo. They also observed that people with a better understanding of ecological features were willing to pay more to avoid the extinction of species. Rogers (2013) has shown that public and expert opinion about restoration efforts can diverge, especially when 
the public have a limited understanding and knowledge. When setting the objectives of restoration programs, there is a risk of misalignment of social and environmental objectives if governments rely only on scientific values.

\section{Some benefits from restoration projects could be privately captured, which would then facilitate acceptance of restoration projects}

Restored ecosystems can generate ecosystem services, both on-farm and off-farm. Off-farm ecosystem services include changes in water and air quality, and protection of endangered species. On-farm ecosystem services include reduction in soil erosion, shelter for grazing animals, improved soil fertility, and increased recreational benefits. The benefits of these services are captured by the participating landholders (Polyakov et al. 2015). There is evidence to suggest that some landholders may receive personal non-use values from undertaking restoration activities. For example, Greiner and Gregg (2011) found that, in some cases, farmers are more strongly motivated by stewardship aspirations than economic and social goals. Three motivation factors - economic/financial, conservation and lifestyle, and social - were found to motivate grazier management in Northern Australia. Jellinek et al. (2013) found large-scale revegetation on agricultural properties was more likely to occur where off-farm income is available and/or where the landholder has a preference to achieve environmental rather than production goals.

Understanding the preferences and behavioural dynamics of landholders is important to the success of ecological restoration activities on private land. Landholders who receive high private benefits (including non-monetary benefits) from ecological restoration would be more willing to participate in programs with lower rates of government support or incentives, which could ultimately reduce their public cost and increase their cost-effectiveness (see Chapter 14). 


\section{Economic incentives can play a crucial role in motivating private landholders to participate, but may not be sufficient on their own}

There are many studies providing evidence on the importance of economic incentives in facilitating the adoption of conservation practices by landholders (see Chapter 21). However, economic incentives are not the only drivers of adoption. As Greiner and Gregg (2011) observe, it is not enough to simply pay farmers to undertake restoration activities. Factors such as resource constraints, a lack of external support, uncertainty over the future of the property, and a lack of industry cooperation can inhibit adoption of conservation practices. The influence of these factors is likely to vary between different types of landholders (e.g. lifestyle or commercial farmers) and between individuals (Pannell and Wilkinson 2009; Welsch et al. 2014). For example, Welsch et al. (2014) found that lifestyle landholders have more property in woody vegetation than dairy and beef/sheep landholders, and were more likely to increase the amount of vegetation in the future. Although lifestyle landholders may be more willing to participate in conservation practices for non-economic reasons, Pannell and Wilkinson (2009) caution that the learning and transaction costs are likely to be higher for this type of landholder.

Pannell (2008) provides a useful framework to help policymakers select the most effective policy mechanism to encourage change by landholders (see Chapter 18). This framework includes economic mechanisms (e.g. paying for services and regulation of activities) and non-economic mechanisms (e.g. new technology and extension). As noted by Pannell (2008), extension plays an important role as a policy mechanism, and should be applied when public and private net benefits are high.

\section{Conclusion}

The issue of restoring ecosystem services on private lands presents a unique setting due to the high cost of implementation, high levels of uncertainty in environmental outcomes, and high probability 
that the program objectives are influenced by social values and the impact of people's loss aversion behaviour. Decision makers need to be aware of these issues and take them into account when planning and implementing restoration projects. For example, by identifying landholder's preferences for different restoration objectives, it might be possible to match landholders with restoration programs that fit their preferences, facilitating the acceptability of the restoration program. Being able to direct restoration programs towards a group of landholders with high environmental motivations could help conservation agencies to deliver restoration projects more costeffectively, as they might be willing to deliver environmental services at lower costs - although it is worth noting the potential issues with the equity of how funds are dispersed. Careful applications of these and similar lessons will help improve the efficiency and uptake of restoration projects in agri-environmental schemes.

\section{Acknowledgements}

The authors would like to acknowledge funding and support received from the National Environmental Research Program and the Centre of Excellence for Environmental Decisions. We thank Caroline Mitchell for proofreading the document. We would also like thank the reviewers and editors of the book for their constructive comments on the chapter.

\section{References}

Alam, K. (2011) 'Public attitudes toward restoration of impaired river ecosystems: Does residents' attachment to place matter?', Urban Ecosystems 14: 635-53.

Aronson, J., A.F. Clewell, J.N. Blignaut and S.J. Milton (2006) 'Ecological restoration: A new frontier for nature conservation and economics', Journal for Nature Conservation 14: 135-9.

Bennett, A.F., J.Q. Radford and A. Haslem (2006) 'Properties of land mosaics: Implications for nature conservation in agricultural environments', Biological Conservation 133: 250-64. 
Blignaut, J., J. Aronson and M. Wit (2014) 'The economics of restoration: Looking back and leaping forward', Annals of the New York Academy of Sciences 1332: 34-47.

Bullock, J.M., J. Aronson, A.C. Newton, R.F. Pywell and J.M. ReyBenayas (2011) 'Restoration of ecosystem services and biodiversity: Conflicts and opportunities', Trends in Ecology and Evolution 26: $541-9$.

Donald, P.F. and A.D. Evans (2006) 'Habitat connectivity and matrix restoration: The wider implications of agri-environment schemes', Ecology 43: 209-18.

Dorrough, J., P.A. Vesk and J. Moll (2008) 'Integrating ecological uncertainty and farm-scale economics when planning restoration', Journal of Applied Ecology 45: 288-95.

Greiner, R. and D. Gregg (2011) 'Farmers' intrinsic motivations, barriers to the adoption of conservation practices and effectiveness of policy instruments: Empirical evidence from northern Australia', Land Use Policy 28: 257-65.

Haila, Y., K. Henle, E. Apostolopoulou, et al. (2014) 'Confronting and coping with uncertainty in biodiversity research and praxis', Nature Conservation 8: 45-75.

Hobbs, R.J. and V.A. Cramer (2008) 'Restoration ecology: Interventionist approaches for restoring and maintaining ecosystem function in the face of rapid environmental change', Annual Review of Environment and Resources 33: 39-61.

Jellinek, S., K.M. Parris, D.A. Driscoll and P.D. Dwyer (2013) Are incentive programs working?: Landowner attitudes to ecological restoration of agricultural landscapes', Journal of Environmental Management 127: 69-76.

Lindenmayer, D.B., A.D. Manning, P.L. Smith, et al. (2002) 'The focalspecies approach and landscape restoration: A critique', Conservation Biology 16: 338-45.

Manning, A.D., J. Fischer and D.B. Lindenmayer (2006) 'Scattered trees are keystone structures: Implications for conservation', Biological Conservation 132: 311-321. 
Maron, M., R.J. Hobbs, A. Moilanen, et al. (2012) 'Faustian bargains?: Restoration realities in the context of biodiversity offset policies', Biological Conservation 155: 141-8.

McBride, M.F., K.A. Wilson, J. Burger, et al. (2010) 'Mathematical problem definition for ecological restoration planning', Ecological Modelling 221: 2243-50.

Michael, D.R., J.T. Wood, M. Crane, R. Montague-Drake and D.B. Lindenmayer (2014) 'How effective are agri-environment schemes for protecting and improving herpetofaunal diversity in Australian endangered woodland ecosystems?', Journal of Applied Ecology 51: 494-504.

Mitani, Y., Y. Shoji, and K. Kuriyama (2008) 'Estimating economic values of vegetation restoration with choice experiments: A case study of an endangered species in Lake Kasumigaura, Japan', Landscape and Ecological Engineering 4: 103-13.

Pannell, D.J. (2008) 'Public benefits, private benefits, and policy mechanism choice for land-use change for environmental benefits', Land Economics 84: 225-40.

Pannell, D.J. and R. Wilkinson (2009) 'Policy mechanism choice for environmental management by non-commercial "lifestyle" rural landholders', Ecological Economics 68: 2679-87.

Polasky, S., E. Nelson, E. Lonsdorf, P. Fackler and A. Starfield (2005) 'Conserving species in a working landscape: Land use with biological and economic objectives', Ecological Applications 15: 1387-401.

Polyakov, M., D.J. Pannell, R. Pandit, S. Tapsuwan and G. Park (2015) 'Capitalized amenity value of native vegetation in a multifunctional rural landscape', American Journal of Agricultural Economics 97: 299-314.

Raymond, C.M. and G. Brown (2011) 'Assessing conservation opportunity on private land: Socio-economic, behavioral, and spatial dimensions', Journal of Environmental Management 92: 2513-23. 
Robbins, A.S. and J.M. Daniels (2012) 'Restoration and economics: A union waiting to happen?' Restoration Ecology 20: 10-17.

Rogers, A.A. (2013) 'Public and expert preference divergence: Evidence from a choice experiment of marine reserves in Australia', Land Economics 89: 346-70.

Schaich, H. (2009) 'Local residents' perceptions of floodplain restoration measures in Luxembourg's Syr Valley', Landscape and Urban Planning 93: 20-30.

Schultz, E.T., R.J. Johnston, K. Segerson and E.Y. Besedin (2012) 'Integrating ecology and economics for restoration: Using ecological indicators in valuation of ecosystem services', Restoration Ecology 20: 304-10.

Shindler, B., R. Gordon, M.W. Brunson and C. Olsen (2011) 'Public perceptions of sagebrush ecosystem management in the Great Basin', Rangeland Ecology and Management 64: 335-43.

Thomson, J.R., A.J. Moilanen, P.A. Vesk, A.F. Bennett and R. MacNally (2009) 'Where and when to revegetate: A quantitative method for scheduling landscape reconstruction', Ecological Applications 19: 817-28.

Tversky, A. and D. Kahneman (1992) 'Advances in prospect theory: Cumulative representation of uncertainty', Journal of Risk and Uncertainty 5: 297-323.

Welsch, J., B. Case and H. Bigsby (2014) 'Trees on farms: Investigating and mapping woody re-vegetation potential in an intensely-farmed agricultural landscape', Agriculture, Ecosystems and Environment 183: 93-102.

Wilson, K.A., M. Lulow, J. Burger and M.F. McBride (2012) 'The economics of restoration', Forest Landscape Restoration (eds L. David, M. Palle and S. John), Springer, New York, pp. 215-31.

Yoshioka, A., M. Akasaka and T. Kadoya (2014) 'Spatial prioritization for biodiversity restoration: A simple framework referencing past species distributions', Restoration Ecology 22: 185-95. 
This text is taken from Learning from agri-environment schemes in Australia: Investing in biodiversity and other ecosystem services on farms, edited by Dean Ansell, Fiona Gibson and David Salt, published 2016 by ANU Press, The Australian National University, Canberra, Australia. 